\title{
Deglutition pattern in Angle's Class II malocclusion
}

Faculdade de Odontologia - Fundação Hermínio Ometto, Departamento de Ortodontia, Araras, São Paulo, Brasil. Faculdade de Ciências Médicas da Universidade Estadual de Campinas - UNICAMP, Departamento de Desenvolvimento Humano e Reabilitação, Campinas, São Paulo, Brasil. Research support source: Programa Institucional de Bolsas de Iniciação Científica (PIBIC).

Conflict of interests: Nonexistent

\section{(c) (i)}

Received on: December 7, 2018 Accepted on: March 12, 2019

\section{Correspondig address:}

Viviane Veroni Degan

Avenida Dr. Maximiliano Baruto, 500

Jardim Universitário

CEP: $13607-339$ - Araras, São Paulo,

Brasil

E-mail: vvdegan@gmail.com
Ana Clara Morari ${ }^{1}$

https://orcid.org/0000-0002-6368-7407

Patricia Rafaela dos Santos ${ }^{1}$ https://orcid.org/0000-0003-3894-2442

Mariana Nabarrette ${ }^{1}$

https://orcid.org/0000-0002-3501-7852

Willian Cristofoletti ${ }^{1}$

https://orcid.org/0000-0003-1416-1414

Carolina Carmo de Menezes ${ }^{1}$ https://orcid.org/0000-0002-8875-8611

Giovana Cherubini Venezian' https://orcid.org/0000-0003-4643-7964

Mirian Hideko Nagae ${ }^{2}$ https://orcid.org/0000-0002-2401-5317

Viviane Veroni Degan ${ }^{1}$ https://orcid.org/0000-0001-9043-8265

\section{ABSTRACT}

Purpose: to analyze the electromyographic activity of the suprahyoid muscles during deglutition in participants with Angle's Class II malocclusion.

Methods: electromyographic data recordings were performed in the supra-hyoid muscles during swallowing and at rest, in 30 volunteers, 15 Angle's Class I participants and 15 Angle's Class II malocclusion, aged 15-27 years old. The Root Means Square values for both tests were analyzed, and for the deglutition test, the Linear Envelope was used to observe the type of muscle activation pattern.

Results: during the test at rest, there was no significant difference in Root Means Square values $(p=0.22)$ between Class I and Class II subjects. During deglutition, it was found that Angle's Class II subjects had significantly higher RMS values $(p=0.01)$ as compared to Class I volunteers. Regarding the type of muscle activation pattern, there was a significant difference between Class I and Class II participants with a predominance of type 1 peak for Class I and type 2 peak for Class II.

Conclusion: there was a difference in electromyographic recordings during deglutition in participants with Angle's Class II as compared to Class I participants with a tendency towards two contraction peaks, showing a greater imbalance during the function. There was no difference between groups in the rest position.

Keywords: Electromyography; Malocclusion, Angle Class I; Malocclusion, Angle Class II; Deglutition 


\section{INTRODUCTION}

Angle's Class II malocclusion is defined as an anteroposterior discrepancy, that is, in the molar sagittal relationship, even though there may not always be basal bone affected. When involved, alterations in sagittal position of the maxilla and/or mandibular are shown ${ }^{1,2}$.

According to Angle's classification, Class II malocclusion is characterized by the position of the upper first molar in relation to the lower first molar in which the mesiobuccal cusp of the upper first molar is positioned anteriorly in relation to the buccal groove of the lower first molar. First division is characterized by protrusion of the upper incisors, which present a labial inclination. It represents a frequent problem, affecting close to $55 \%$ of the Brazilian population ${ }^{1,3}$.

Dentofacial deformities determine specific myofunctional characteristics peculiar to the type of disproportion, such as alteration in habitual lip and tongue positions, muscular asymmetries, temporomandibular joint dysfunctions, and abnormal mastication, deglutition, speech and respiratory function ${ }^{4-6}$.

Deglutition is defined as the act of swallowing, resulting from a complex and dynamic neuromotor mechanism, which aims to transport the food bolus from the mouth to the stomach effectively. It requires precise coordination from the stomatognathic system and the structures of which it is composed ${ }^{7,8}$.

The suprahyoid muscles are considered to be strategic for deglutition, since they participate in motor reflex mechanisms, lowering and stabilization of the mandible, elevation and forward movement of the hyoid bone, and have insertion with tongue musculature ${ }^{9,10}$.

Surface electromyography (SEM) registers electric potentials of skeletal muscle. It evaluates muscular function, making it a useful tool for the study of muscle dynamics during functions of the stomatognathic system, including deglutition. It contributes to better comprehension of the physiological mechanism of normal and pathological deglutition ${ }^{11-15}$.It is a method that is non-invasive, reproducible and of little discomfort for the patient during the exam ${ }^{11,16}$.

Muscular behavior can be determined by studying the relation between the frequency and intensity of the electric registers. The electric signal is obtained in microvolts $(\mu \mathrm{v})$, which can follow variations in the mathematical process of the signal, such as the minimum and maximum amplitude values, integrated value, the linear envelope, spectral or signal frequency variables. The root mean square (RMS) of the linear envelope in the time domain can be used to analyze when the rectified signal is passed through a filter to decrease high frequency fluctuations, allowing a clear evaluation of the electromyographic signal amplitude ${ }^{14,17}$.

The correlation of biomechanical events of deglutition has been described in the literature and its characteristics associated with electromyography establish the suprahyoid musculature as that which reflects the verification of this functional event. The characterization of deglutition using surface electromyography is attained by tracing electromyographic signals such as the increase in amplitude of these signals in relation to basal muscle tension (habitual posture), followed by a maximum amplitude peak of electromyographic signals and then return to the basal level of muscle contraction ${ }^{16}$.

An electromyographic analysis of deglutition can highlight differences in muscular activity, which can be identified and correlated with occlusion?

The objective of this study was to evaluate the electromyographic activity of the supra-hyoid muscles during deglutition in participants with Angle's Class II, division 1 malocclusion.

\section{METHODS}

This prospective observational transversal study was approved by the Ethics in Research Committee of Fundação Hermínio Ometto (FHO) protocol number 20391513.0.0000.5385.

All volunteers signed a consent form after the procedures of the study were explained.

The sample was composed of participants aged 15-27 years, of both genders, 15 having Angle's Class I molars and 15 having Class II, first division malocclusion.

The volunteers obeyed the inclusion and exclusion criteria which were: the patients were not mouthbreathers, no tooth loss, no signs of temporomandibular joint dysfunction, no facial pain complaints, no use of muscle relaxant medication and no previous orthodontic treatment.

All procedures for the acquisition of the electromyographic signals were performed according to the guidelines established by the International Society of Electromyography and Kinesiology (ISEK $)^{7,9}$.

Electromyographic activity was registered by surface electromyography using the Miotool $400 \AA$ (Miotec) equipment, 14 Bit signal acquisition, 2000 samples/second per channel acquisition rate, common rejection mode of $110 \mathrm{db}$. The Miograph software was 
used with SDS 500 sensors, sample frequency of 2000 $\mathrm{Hz}$, low-pass filter of $20 \mathrm{~Hz}$ and high-pass filter of 500 $\mathrm{Hz}$. The Root Mean Square (RMS) values were calculated to represent the mean amplitude of the electromyographic signal ${ }^{7}$.

The electromyography room was adapted to reduce environmental interferences in the electromyographic registers. Electric and electromagnetic isolation was achieved by grounding the electric network that supplies the environment, having an independent electric network, and turning off and removing light sources (lamps, light bulbs and reactors). Volunteers, researchers and electromyographic equipment were positioned on rubber mats.

Before placing the electrodes, the area of the supra-hyoid muscles was cleaned with cotton and $70 \%$ alcohol. When necessary, men were asked to shave with disposable razors.

Child-size disposable $\mathrm{Ag} / \mathrm{AgCl}$ Meditrace Kendall electrodes were trimmed and positioned on the suprahyoid muscle region from the median below the chin in the posterior-anterior direction. The electrode fixation site was determined by testing the deglutition function, by asking the volunteer to swallow and thus identifying the position of the muscle. The reference electrode was positioned at the manubrium of the sternum. The interelectrode distance was $1 \mathrm{~cm}$.

The tests were performed with the volunteers seated, feet on the floor and the head at the natural position.

The acquisition of the electromyographic signal was achieved by performing three tests at rest and three tests during deglutition. At rest, electromyographic signal was collected over a period of 10 seconds. For the deglutition test, the volunteer received $5 \mathrm{ml}$ of water, which was deposited into the oral cavity using a needleless disposable syringe. The volunteers held the liquid while awaiting verbal command to swallow during the 5-second protocol.

The RMS data values were not normalized because a previous study demonstrated that the data normalized by means and peaks showed differences between the groups. However, the differences decrease in relation to those observed in the original non-normalized data, due to the fact that the muscles studied were of low caliber ${ }^{7}$.

The data was analyzed using the mean of the three tests at rest and during deglutition in RMS values, and by the type of tracing produced by the linear envelope during deglutition.

The types of tracings were classified as: predominantly one peak (Figure 1), in which a defined peak could be observed, considered adequate (type 1 tracing); more than one peak (Figure 2), in which the presence of more than one contraction episode during deglutition could be observed (type 2 tracing); and non-defined peak (Figure3), classified by the absence of a defined peak (type 3 tracing) ${ }^{16}$.

The data was analyzed for homogeneity and normality. The RMS value data at rest and during deglutition were transformed with a logarithmic function and underwent the t-test for independent samples with a 5\% significance level. The data for each peak type underwent the Mann-Whitney test with a 5\% significance level.

\section{RESULTS}

The results in RMS values showed that there was no significant difference $(p=0.22)$ between Class I and Class II participants at rest (Table 1). It was verified that Class II participants show significantly higher values $(p=0.01)$ than Class I participants during deglutition (Table 1).

Table 1. Mean, standard deviation and p-values of the electromyography datas in root mean square values obtained during deglutition in suprahyoid muscles

\begin{tabular}{|c|c|c|c|c|c|c|}
\hline \multirow[b]{2}{*}{ Groups } & \multicolumn{3}{|c|}{ RMS Rest } & \multicolumn{3}{|c|}{ RMS Deglutition } \\
\hline & Average & $\begin{array}{l}\text { Standard } \\
\text { Deviation }\end{array}$ & & Average & $\begin{array}{l}\text { Standard } \\
\text { Deviation }\end{array}$ & \\
\hline Class I & 2.48 & 1.20 & $\mathrm{a}$ & 9.81 & 8.95 & $\mathrm{~b}$ \\
\hline Class II & 3.48 & 2.57 & $\mathrm{a}$ & 16.95 & 9.86 & $\mathrm{a}$ \\
\hline & & & $p=0.22$ & & & $p=0.01$ \\
\hline
\end{tabular}

Values marked by distinct letters are significantly different from each other according to t-test for independent samples $(p<0.05)$.

Legend: RMS = root mean square 
Table 2. Type of tracing produced by the linear envelope during deglutition in Angle's Class I and Class II malocclusion

\begin{tabular}{ccccc}
\hline \multirow{2}{*}{ Groups } & \multicolumn{5}{c}{ Type of peak } \\
\cline { 2 - 5 } & Median & $\mathbf{2 5 \%}$ & $\mathbf{7 5 \%}$ & \\
\hline Class I & 1.000 & 1.000 & 1.750 & $\mathrm{~B}$ \\
Class II & 2.000 & 2.000 & 3.000 & $\mathrm{~A}=0.02$ \\
\hline
\end{tabular}

Values marked by distinct letters are significantly different from each other according to Mann-Whitney test $(p<0.05)$.

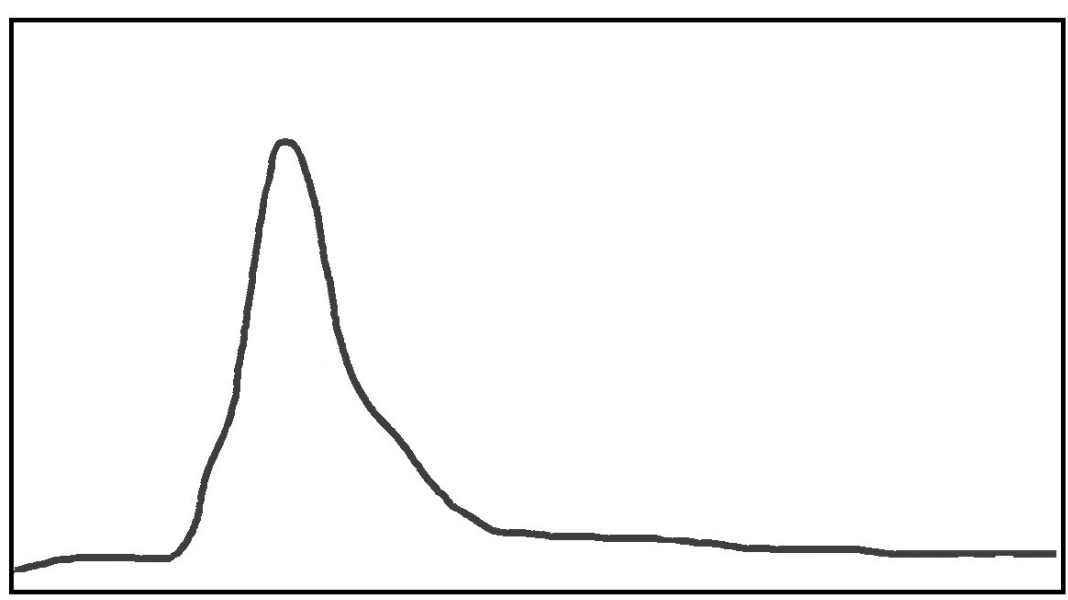

Figure 1. Type 1 tracing - predominantly one peak

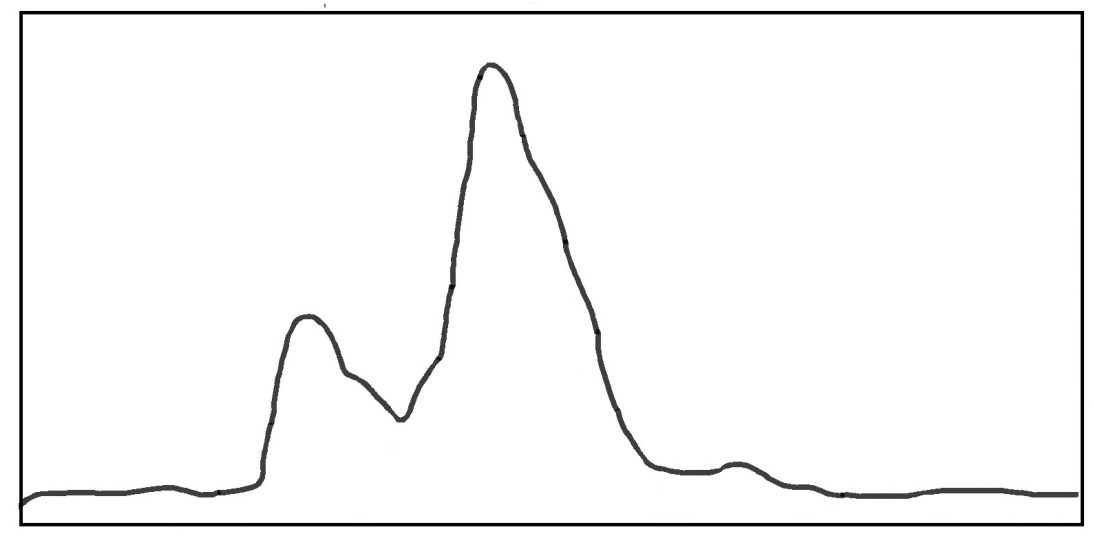

Figure 2. Type 2 tracing - more than one peak

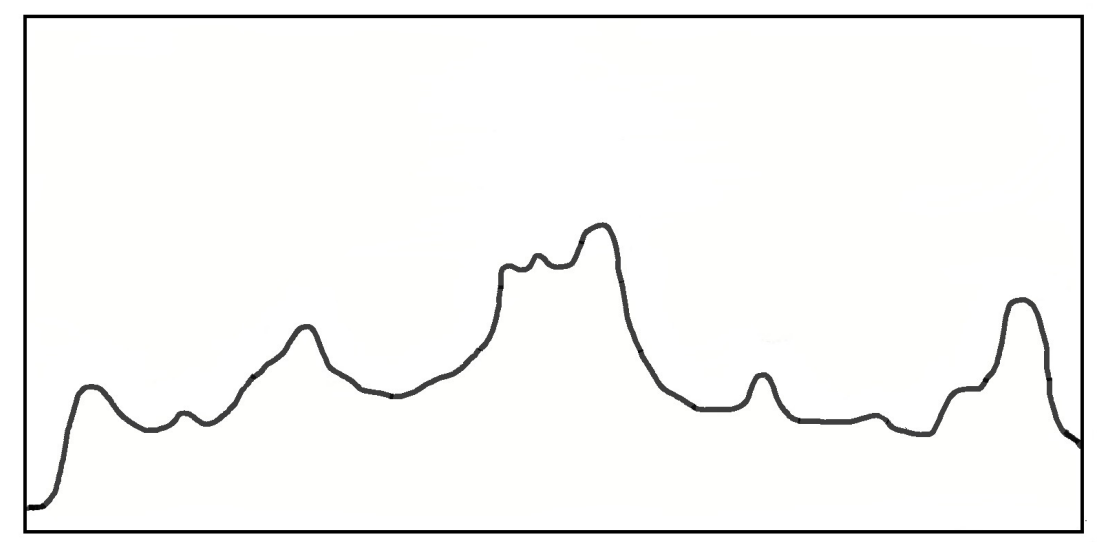

Figure 3. Type 3 tracing - nondefined peak 
With regard to the type of peak, a significant difference was verified between Class I and Class II participants. Class I participants had predominantly one peak and Class II participants had more than one peak.

\section{DISCUSSION}

Deglutition is a complex sensory-motor mechanism that involves sequential excitation and inhibition of the central nervous system at different levels, and thus involves the whole stomatognathic system ${ }^{16}$.

A conjoint equilibrated action of the maxillomandibular structures with the muscular system is of utmost importance so that actions such as mastication, deglutition, speech and respiration occur efficiently $y^{7,18}$.

The suprahyoid muscles have an important role in deglutition, participate in motor reflexes, and lower and stabilize the mandible ${ }^{9,10}$.

For efficient deglutition, the mandible assumes a fixed, stable position, by intercuspation of the occlusal surfaces, immediately before the tongue pushes the food bolus towards the oropharynx. In turn, stabilization of the mandible allows the suprahyoid muscles to contract and consequently, movement of the hyoid bone upward and forward, guaranteeing safe deglutition. There is evidence that the mandibular rest position can be altered as a result of occlusal interferences, temporomandibular joint dysfunction, stress, nasal obstruction and head position ${ }^{19}$.

Although studies show evidence for differences in electromyographic activity between participants with different occlusal classifications ${ }^{19-21}$, in this experiment, there was no difference observed between the two types of occlusion studied at rest.

During the deglutition test, analysis of RMS values of Angle's Class I participants showed that the muscles worked in a more balanced manner during function. This fact was also observed in another study'.

The most prevalent type of peak was Type 1, with only one peak during function. The literature points to the expectation of an electromyographic curve with only one peak, with gradual increase and decrease in muscular activity ${ }^{16}$.

In Class II participants, a difference in RMS values was demonstrated in comparison to the Class I group ${ }^{21}$. Higher RMS values were obtained in Class II subjects, demonstrating a need for greater muscular effort, probably resulting in maxillomandibular and key occlusal fitting disproportion, and a prevalence of two contraction peaks ${ }^{7}$.
Another study that evaluated electromyographic activity during deglutition suggested that, in volunteers with normal occlusion, the mandible is stabilized during deglutition due to the contraction of the mandible elevator muscles and the anterior suprahyoid muscles. These muscles elevate the hyoid bone to its highest position, and consequently, the anterior third of the tongue reaches the hard palate. This strong elevation of the tongue shortens the floor of the mouth, which, together with the elevation of the hyoid bone, promotes a strong recruitment of the anterior suprahyoid muscles during deglutition ${ }^{9}$.

Angle's Class II participants presented a prevalence for Type 2 tracings. A modification in their morphology such as having a protruded maxilla, retruded mandible, or a combination of both, can promote functional adaptations, such as modifying tongue position and muscular activity for correct deglutition, in which the muscle requires more activity to perform deglutition ${ }^{7}$.

To know how stomatognathic functions occur in their normality and how the performance and modified according to the positioning of the bone and dental bases is essential for the speech-language pathologist to plan the myofunctional treatment ${ }^{22,23}$.

\section{CONCLUSION}

From this study it can be concluded that there was a difference in deglutition between Angle's Class II participants and Class I participants, with a tendency towards two contraction peaks, showing grater unbalance during function. There was no difference between the groups at rest.

\section{ACKNOWLEDGMENTS}

Programa Institucional de Bolsas de Iniciação Científica (PIBIC).

\section{REFERENCES}

1. Joshi N, Hamdan AM, Fakhouri WD. Skeletal malocclusion: a developmental disorder with a life-long morbidity. J Clin Med Res. 2014;6(6):399-408.

2. Almeida KCM, Raveli TB, Vieira CIV, Pinto AS, Raveli DB. Influence of the cranial base flexion on Class I, II and III malocclusions: a systematic review. Dental Press J Orthod. 2017;22(5):56-66.

3. Rana N, Qu YY, Wei Y, Liu L. Comparison of cephalometric hard and soft tissues of adolescents with Angle Class II Division 1 Malocclusion between 
northern chinese population and northern indian population. Chin J Dent Res. 2017;20(1):33-42.

4. Menezes LF, Rocha Neto AM, Paulino CEB, Laureano Filho JR, Studart-Pereira LM. Tongue pressure and endurance in patients with Class II and Class III malocclusion. Rev. CEFAC. 2018;20(2):166-74.

5. Sun H, Shang HT, He LS, Ding MC, Su ZP, Shi YL. Assessing the quality of life in patients with dentofacial deformities before and after orthognathic surgery. JOral Maxillofac Surg. 2018;76(10):2192-201.

6. Migliorucci RR, Passos DCBOF, Felix GB. Orofacial myofunctional therapy program for individuals undergoing orthognathic surgery. Rev. CEFAC. 2017;19(2):277-88.

7. Nagae MH, Alves MC. Estudo eletromiográfico da deglutição na musculatura supra-hióidea em sujeitos Classe I e III de Angle. Rev. CEFAC. 2009;11(3):355-62.

8. Caldas ASC, Coelho WK, Ribeiro RFG, Cunha DA, Silva HJ. Motor imagery and swallowing: a systematic literature review. Rev. CEFAC. 2018;20(2):247-57.

9. Souza DR de, Semechini TA, Kröll LB, Berzin F. Oral myofunctional and electromyographic evaluation of the anterior suprahyoid muscles and tongue thrust in patients with Class II/1 malocclusion submitted to first premolar extraction. J Appl Oral Sci. 2007;15(1):24-8.

10. Lobo MB, Luccia N, Nogueira AC, Silvério CC. The effect of the neuromuscular electrical stimulation on the suprahyoid muscle activity during swallowing in subjects with dysphagia. Rev. CEFAC. 2016;18(5):1179-88.

11. Pearson WG Jr, Hindson DF, Langmore SE, Zumwalt AC. Evaluating swallowing muscles essential for hyolaryngeal elevation by using muscle functional magnetic resonance imaging. Int J Radiat Oncol Biol Phys. 2013;85(3):735-40.

12. Kothari M, Stubbs PW, Pedersen AR, Jensen J, Nielsen JF. Reliability of surface electromyography measurements from the suprahyoid muscle complex. J Oral Rehabil. 2017;44(9):683-90.

13. Pernambuco LA, Silva HJ, Nascimento GKBO, Silva EGF, Balata PMM, Santos VS et al. Electrical activity of the masseter during swallowing after total laryngectomy. Braz JOtorhinolaryngol. 2011;77(5):645-50.
14. Dellavia C, Rosati R, Musto F, Pellegrini G, Begnoni G, Ferrario VF. Preliminary approach for the surface electromyographical evaluation of the oral phase of swallowing. J Oral Rehabil. 2018 doi: 10.1111/ joor.12641.

15. Freitas GS, Mituuti CT, Furkim AM, BusanelloStella AR, Stefani FM, Arone MMAS et al. Electromyography biofeedback in the treatment of neurogenicorofacial disorders: systematic review of the literature. Audiol Commun Res. 2016;21:e1671.

16. Bianchini EMG, Kayamori F. Surface electromyographic characterization of swallowing in subjects with and without swallowing disorders. Rev. CEFAC. 2012;14(5):872-82.

17. Marchetti PH, Duarte M. Instrumentação em eletromiografia. Laboratório de Biofísica, Escola de Educação Física e Esporte. São Paulo: Universidade de São Paulo; 2006. Disponível em: http://demotu.org/pubs/EMG.pdf

18. Prates LS, Gois M, Berwig LC, Blanco-Dutra AP, Busanello-Stella AR, Silva AMT. Clinical and electromyographic evaluation of masticationwithin different facial growth patterns. Rev. CEFAC. 2016;18(1):104-11.

19. Trevisan ME, Weber P, Ries LGK, Corrêa ECR. Relationship between the electrical activityof suprahyoid and infrahyoid muscles during swallowing and cephalometry. Rev. CEFAC. 2013;15(4):895-903.

20. Ferreira JTL, Lima MRF, Pizzolato LZ. Relation between Angle Class II malloclusion and deleterious oral habits. Dental Press J. Orthod. 2012;17(6):111-7.

21. Sousa V, Paço $M$, Pinho T. Implicações da respiração oral e deglutição atípica na postura corporal. Nascer e crescer. 2017;26(2):89-94.

22. Trench JA, Araújo RPC. Dentofacial deformities: orofacial myofunctional characteristics. Rev. CEFAC. 2015;17(4):1202-14.

23. Silva AP, Sassi FC, Andrade CRF. Oral-motor and electromyographic characterization of patients submitted to open and closed reductions of mandibular condyle fracture. CoDAS. 2016;28(5):558-66. 